Research Article

\title{
Fracture Mechanism in Overlying Strata during Longwall Mining
}

\author{
Zhengyi Ti $\mathbb{D}$, ${ }^{1}$ Jiazhen Li $\mathbb{D},{ }^{1}$ Meng Wang $\mathbb{D},{ }^{1}$ Kang Wang $\left(\mathbb{D},{ }^{1}\right.$ Zhupeng Jin, ${ }^{2}$ \\ and Caiwang Tai ${ }^{1}{ }^{1}$ \\ ${ }^{1}$ College of Mining Engineering, Liaoning Technical University, Fuxin 123000, China \\ ${ }^{2}$ School of Mining Engineering, Heilongjiang University of Science and Technology, Harbin 150027, China
}

Correspondence should be addressed to Jiazhen Li; 1.jz2000@163.com

Received 21 April 2021; Revised 22 May 2021; Accepted 29 May 2021; Published 21 June 2021

Academic Editor: chao xu

Copyright (c) 2021 Zhengyi Ti et al. This is an open access article distributed under the Creative Commons Attribution License, which permits unrestricted use, distribution, and reproduction in any medium, provided the original work is properly cited.

We used the key stratum theory to establish a more realistic thin-plate mechanical model of elastic foundation clamped boundary and study the fracture mechanism of overlying strata during longwall mining. We analyzed the fracture characteristics and factors affecting fracture of the key stratum combined with the Mohr-Coulomb yield criterion. Besides, we used numerical simulation methods to verify the evolution pattern of the overlying strata fracture. The results show that the fracture mechanisms of the elastic foundation clamped structure's key stratum varied depending on the position under longwall mining. The advanced coal wall area of the upper surface is a compressive-shear fracture. The center area of the lower surface is a tensile fracture. With the increase of the excavation length and the load of the key stratum, the central area and the advanced coal wall area of the long side are fractured before the advanced coal wall area of the short side. With the increase of flexural rigidity of the key stratum, the advanced coal wall area of the long side fractures before the central area and the advanced coal wall area of the short side. With the increase of the foundation modulus and the advanced load of the key stratum, the central area fractures before the surrounding advanced coal wall area. The advanced influence distance was positively correlated with the key stratum's flexural rigidity and advanced load and negatively correlated with the foundation modulus and excavation length. The advanced influence distance was not affected by the load of the key stratum. The numerical simulation results show that, with the increase of the mining area, the fracture trace of overlying strata in goaf extended to the coal wall's interior. The fracture range of overlying strata is larger than that of the miningd: area. This study has a practical value for water disasters, gas outbursts, and rock strata control.

\section{Introduction}

Longwall mining is easy to form large-scale goaf. It results in a stress state and spatial structure redistribution of overlying strata, bringing many security issues, including rockburst and water disasters [1]. Therefore, it is necessary to thoroughly study the fracture mechanism of overlying strata by longwall mining.

In the present research, the mechanical model of overlying strata after longwall mining has been simplified as fixed or simply supported structures. It was considered that the fracture space of the overlying strata above the goaf presents a positive trapezoidal distribution [2-5]. However, previous studies have ignored the influence of elastic deformation of the supporting coal-rock mass on overlying strata fracture [6-8]. The predicted overlying strata fracture morphology was not consistent with the actual mining [9]. Guo et al. established the fractured water-conducting zone (FWCZ) based on the fixed beam theory. They considered that the fracture morphology of the overlying strata above the goaf was trapezoidal $[10,11]$. Sun et al. established the analogous hyperbola subsidence model (AHSM) based on the fixed beam theory. They considered that the subsidence boundary of the inner overlying strata is a curve that is convex toward the goaf [12]. Many measured data showed that the fracture range of overlying strata above the goaf is greater than the mining range [13-16]. Shi et al. confirmed that the movement range of overlying strata and the influence distance on the front of the working face expanded based on the microseismic monitoring results [17]. Cheng et al. established the zoning model of the roof strata movement based on microseismic monitoring. They divided 
the area above the supporting coal pillar into a shear stress control zone [18].

The fracture mechanism of overlying strata is the basis of rockburst prevention, surface subsidence control, and gas prevention [19]. Therefore, it is of great significance for effective prevention and disaster control to establish a mining-induced overlying strata mechanical model in line with the actual mining and study the evolution pattern of overlying strata fracture with this model [20].

We established a thin-plate mechanical model of elastic foundation clamped boundary based on key stratum theory. We studied the fracture mechanism and factors affecting the fracture of overlying strata. Additionally, we used the Universal Distinct Element Code (UDEC) to simulate the evolution pattern of the overlying strata fracture caused by mining. These results provide a complete understanding of the rock strata movement induced by mining.

\section{The Mechanical Model of Elastic Foundation Clamped Boundary}

2.1. Key Stratum Theory. Academician Qian indicated that the thick and hard strata were defined as the key stratum (KS) that play a decisive role in strata movement [21]. When the key stratum is deformed or fractured, the strata controlled by the key stratum are also synchronized with subsidence and collapse. According to the control range of the key stratum, they can be divided into the primary key stratum (PKS) and inferior key stratum (IKS). PKS controls all the overlying strata until the surface. IKS only controls the local strata.

2.2. Mechanical Models of the KS. When mining the coal, the immediate roof fractures first. Above the goaf, the KS is in a state of suspension. According to the KS theory, the KS is clamped by relatively weak rock strata under mining geological conditions, which have a weak ability to limit the KS movement. Therefore, the KS boundary conforms to the elastic clamped boundary condition rather than the rigidly fixed boundary condition [22]. Generally, when the KS fractures, its thickness is less than $1 / 8-1 / 5$ of the short side length of the mining size, which meets the basic assumption of elasticity [23]. For simplification, taking the horizontal KS as an example, we establish the thin-plate mechanical model under the clamped boundary condition of the elastic foundation [24-26].

The mechanical model of the KS is shown in Figure 1. Figure 1 is the KS plane structure. The goaf is below the central area of the KS, and the elastic foundation clamped area is around it. An infinite distance from the goaf is a fixed boundary. The $x$-axis is the direction of the longwall face, namely, the long side. The $y$-axis is the direction of excavation, namely, the short side. The stress state of the KS is divided into two situations. When the rock stratum is the PKS, the stress state of the KS is shown in Figure 1. The KS above the elastic foundation area is in the stress equilibrium state. Only the KS above the goaf-loaded $q_{1}$ is the load by its self-weight and a load of overlying soft strata. When the rock stratum is an IKS, the stress state of the KS is shown in Figure 1(c). The KS above the elastic foundation zone also loaded the transfer load $q_{2}$ of other KS above.

Introducing the Winkler mechanics model, the foundation modulus $k$ of elastic foundation zone is as follows [22]:

$$
\frac{1}{k}=\frac{1}{k_{c}}+\frac{1}{k_{i}},
$$

where $k_{c}$ is the coal seam's elastic coefficient, $\mathrm{GPa} / \mathrm{m}$; $k_{c}=E_{c} / h_{c}$, where $E_{c}$ is the elastic modulus of the coal seam, $\mathrm{GPa} ; h_{c}$ is the thickness of coal seam; $k_{i}$ is the elastic coefficient of other strata.

The load $q_{1}$ of the KS above goaf is as follows [21]:

$$
q_{1}=\frac{E_{1} \delta_{1}^{3}\left(\gamma_{1} \delta_{1}+\gamma_{2} \delta_{2}+\cdots+\gamma_{n} \delta_{n}\right)}{E_{1} \delta_{1}^{3}+E_{2} \delta_{2}^{3}+\cdots+E_{n} \delta_{n}^{3}}
$$

where $\delta_{1}$ is the thickness of the KS, $\mathrm{m} ; \gamma_{1}$ is the volume force of the KS, MN/m $\mathrm{m}^{3} ; E_{1}$ is the elastic modulus of the $\mathrm{KS}, \mathrm{GPa} ; \delta_{2} \ldots \delta_{n}$ are the thickness of rock strata controlled by KS, $\mathrm{m} ; \gamma_{2} \ldots \gamma_{n}$ are the volume force of rock strata controlled by $\mathrm{KS}, \mathrm{MN} / \mathrm{m}^{3} ; E_{2} \ldots E_{n}$ are the elastic modulus of rock strata controlled by KS, GPa.

The transfer load of the KS above the elastic foundation zone can be determined by the inversion and superposition of the supporting reaction forces of other KS above it, for example, when there are two KS in the overlying strata. First, obtain the subsidence value of the elastic foundation zone according to the PKS mechanics model. Invert the transfer load of the PKS to the elastic foundation according to the foundation modulus, and finally apply transfer load to the IKS mechanics model. $q_{2}$ is as follows:

$$
q_{2}=k w
$$

where $w$ is the subsidence value of the elastic foundation zone, $\mathrm{m}$.

According to the theory of elasticity, the basic differential equation of the KS above goaf is as follows [23]:

$$
\frac{\partial^{4} w_{1}}{\partial x^{4}}+2 \frac{\partial^{4} w_{1}}{\partial x^{2} \partial y^{2}}+\frac{\partial^{4} w_{1}}{\partial y^{4}}=\frac{q_{1}}{D}
$$

where $w_{1}$ is the deflection function of the KS above the goaf and $D$ is the flexural rigidity of the $\mathrm{KS}, \mathrm{GPa} \cdot \mathrm{m}^{3}$.

$$
D=\frac{E_{1} \delta_{1}^{3}}{12\left(1-\mu_{1}^{2}\right)}
$$

where $\mu_{1}$ is the Poisson ratio of the KS.

The basic differential equation of the PKS above the elastic foundation zone is as follows:

$$
\frac{\partial^{4} w_{2}}{\partial x^{4}}+2 \frac{\partial^{4} w_{2}}{\partial x^{2} \partial y^{2}}+\frac{\partial^{4} w_{2}}{\partial y^{4}}-\frac{k w_{2}}{D}=0
$$




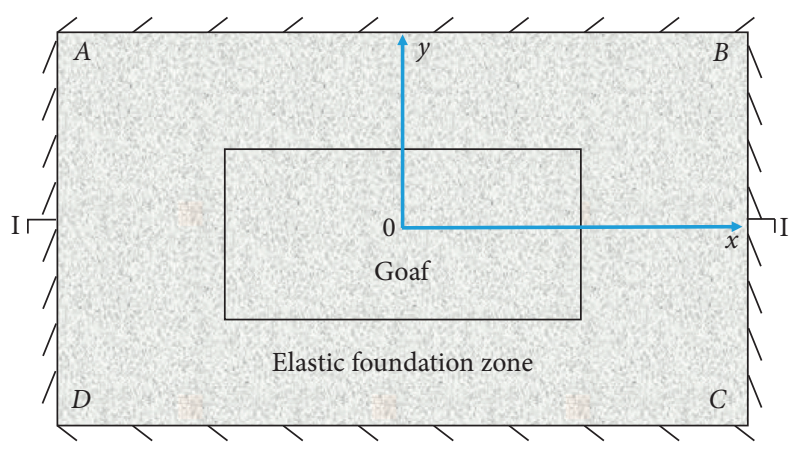

(a)

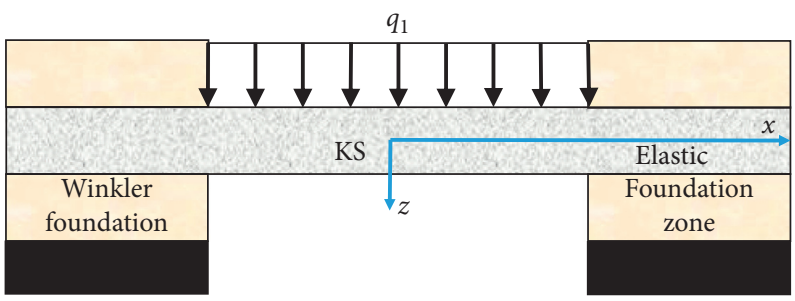

(b)

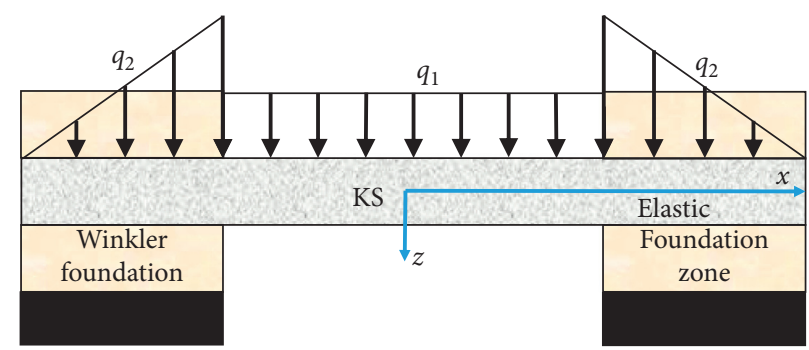

(c)

FIgure 1: The mechanical model of the KS: (a) the KS plane structure; (b) the stress state of the PKS; (c) the stress state of the IKS.

The basic differential equation of the IKS above the elastic foundation zone is as follows:

$$
\frac{\partial^{4} w_{2}}{\partial x^{4}}+2 \frac{\partial^{4} w_{2}}{\partial x^{2} \partial y^{2}}+\frac{\partial^{4} w_{2}}{\partial y^{4}}=\frac{q_{2}}{D}-\frac{k w_{2}}{D}
$$

where $w_{2}$ is the deflection function of the KS above the elastic foundation zone.

The differential equation of the fixed boundary conditions around the elastic foundation zone is as follows:

$$
\left\{\begin{array}{c}
A B\left\{w_{2}=0 \frac{\partial w_{2}}{\partial y}=0\right. \\
C D\left\{w_{2}=0 \frac{\partial w_{2}}{\partial y}=0\right. \\
A D\left\{w_{2}=0 \frac{\partial w_{2}}{\partial x}=0\right. \\
B C\left\{w_{2}=0 \frac{\partial w_{2}}{\partial x}=0\right.
\end{array}\right.
$$

2.3. Finite Difference Method. The basic differential equations in different calculation zones are different, and it is not easy to obtain unified functional solutions. Therefore, the finite difference method is used. The finite difference method uses difference equations to express the basic differential equations and boundary conditions. It replaces the problem of solving differential equations with solving algebraic equations. Two parallel lines with equal spacing $h$ and parallel to the coordinate axis can be woven into a grid on the thin-plate middle plane. As shown in Figure 2, the intersection of the grid is called the node.

The basic difference equation of the KS above goaf is as follows:

$$
\begin{aligned}
\frac{q_{1} h^{4}}{D}= & 20 w_{1}(i, j)-8\left[\begin{array}{c}
w_{1}(i+1, j)+w_{1}(i, j+1) \\
+w_{1}(i-1, j)+w_{1}(i, j-1)
\end{array}\right] \\
& +2\left[\begin{array}{c}
w_{1}(i+1, j-1)+w_{1}(i+1, j+1) \\
+w_{1}(i-1, j+1)+w_{1}(i-1, j-1)
\end{array}\right] \\
& +\left[\begin{array}{c}
w_{1}(i+2, j)+w_{1}(i, j+2) \\
+w_{1}(i-2, j)+w_{1}(i, j-2)
\end{array}\right] .
\end{aligned}
$$




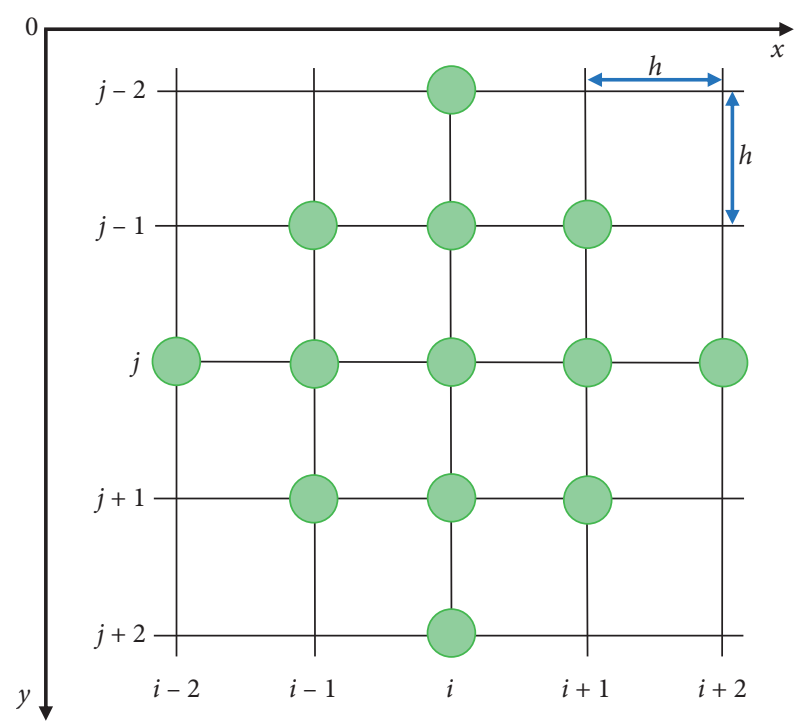

Figure 2: Finite difference grid.

The basic difference equation of the PKS above the elastic foundation zone is as follows:

$$
\begin{aligned}
0= & \left(20+\frac{k h^{4}}{D}\right) w_{2}(i, j)-8\left[\begin{array}{c}
w_{2}(i+1, j)+w_{2}(i, j+1) \\
+w_{2}(i-1, j)+w_{2}(i, j-1)
\end{array}\right] \\
& +2\left[\begin{array}{c}
w_{2}(i+1, j-1)+w_{2}(i+1, j+1) \\
+w_{2}(i-1, j+1)+w_{2}(i-1, j-1)
\end{array}\right] \\
& +\left[\begin{array}{l}
w_{2}(i+2, j)+w_{2}(i, j+2) \\
+w_{2}(i-2, j)+w_{2}(i, j-2)
\end{array}\right]
\end{aligned}
$$

The basic difference equation of the IKS above the elastic foundation zone is as follows:

$$
\begin{aligned}
\frac{q_{2} h^{4}}{D}= & \left(20+\frac{k h^{4}}{D}\right) w_{2}(i, j)-8\left[\begin{array}{c}
w_{2}(i+1, j)+w_{2}(i, j+1) \\
+w_{2}(i-1, j)+w_{2}(i, j-1)
\end{array}\right] \\
& +2\left[\begin{array}{c}
w_{2}(i+1, j-1)+w_{2}(i+1, j+1) \\
+w_{2}(i-1, j+1)+w_{2}(i-1, j-1)
\end{array}\right] \\
& +\left[\begin{array}{c}
w_{2}(i+2, j)+w_{2}(i, j+2) \\
+w_{2}(i-2, j)+w_{2}(i, j-2)
\end{array}\right] .
\end{aligned}
$$

The difference equation of the fixed boundary conditions around the elastic foundation zone is as follows:

$$
\left\{\begin{array}{l}
A D\left\{\begin{array}{l}
w_{2}(i, j)=0 \\
w_{2}(i-1, j)=3 w_{2}(i+1, j)-\frac{w_{2}(i+2, j)}{2}
\end{array}\right. \\
B C\left\{\begin{array}{l}
w_{2}(i, j)=0 \\
w_{2}(i+1, j)=3 w_{2}(i-1, j)-\frac{w_{2}(i-2, j)}{2} \\
C D\left\{\begin{array}{l}
w_{2}(i, j)=0 \\
w_{2}(i, j-1)=3 w_{2}(i, j+1)-\frac{w_{2}(i, j+2)}{2} \\
w_{2}(i, j+1)=3 w_{2}(i, j-1)-\frac{w_{2}(i, j-2)}{2}
\end{array}\right. \\
w_{2}(i, j)=0
\end{array},\right.
\end{array}\right.
$$

According to the difference equations, the algebraic equations are established. The deflection value of each node is solved by the numerical method [27]. Obtain the stress component of each node according to the deflection value. Each stress component and its difference equation and principal stress equation are as follows [23]:

$$
\left\{\begin{array}{l}
\sigma_{x}=-\frac{E z}{1-\mu^{2}}\left(\frac{\partial^{2} w}{\partial x^{2}}+\mu \frac{\partial^{2} w}{\partial y^{2}}\right) \\
\sigma_{y}=-\frac{E z}{1-\mu^{2}}\left(\frac{\partial^{2} w}{\partial y^{2}}+\mu \frac{\partial^{2} w}{\partial x^{2}}\right) \\
\sigma_{z}=-2 q\left(\frac{1}{2}-\frac{z}{\delta}\right)^{2}\left(1+\frac{z}{\delta}\right), z \in\left(-\frac{\delta}{2}, \frac{\delta}{2}\right) \\
\tau_{x y}=\tau_{y x}=-\frac{E z}{1+\mu} \frac{\partial^{2} w}{\partial x \partial y}, \\
\tau_{x z}=\frac{6 F_{S x}}{\delta^{3}}\left(\frac{\delta^{2}}{4}-z^{2}\right), \tau_{x z}=\frac{6 F_{S y}}{\delta^{3}}\left(\frac{\delta^{2}}{4}-z^{2}\right)
\end{array}\right.
$$

where $z$ is the coordinate along the thickness direction of the $\mathrm{KS}, \mathrm{m} ; \sigma$ is the normal stress, $\mathrm{MPa} ; \tau$ is the shear stress, MPa. 


$$
\begin{aligned}
& \sigma_{x}(i, j)=\frac{E z}{\left(1-\mu^{2}\right) h^{2}}\left\{\begin{array}{c}
(2+2 \mu) w(i, j)-[w(i+1, j)+w(i-1, j)] \\
-\mu[w(i, j+1)+w(i, j-1)]
\end{array}\right\} \\
& \left\{\sigma_{y}(i, j)=\frac{E z}{\left(1-\mu^{2}\right) h^{2}}\left\{\begin{array}{c}
(2+2 \mu) w(i, j)-[w(i, j+1)+w(i, j-1)] \\
-\mu[w(i+1, j)+w(i-1, j)]
\end{array}\right\},\right. \\
& \tau_{x y}(i, j)=\frac{E z}{(1+\mu) 4 h^{2}}\left\{\begin{array}{c}
{[w(i+1, j-1)+w(i-1, j+1)]} \\
-[w(i+1, j+1)+w(i-1, j-1)]
\end{array}\right\},
\end{aligned}
$$

$$
\left.\begin{array}{l}
\sigma_{1} \\
\sigma_{3}
\end{array}\right\}=\frac{\sigma_{x}+\sigma_{y}}{2} \pm \sqrt{\left(\frac{\sigma_{x}-\sigma_{y}}{2}\right)^{2}+\tau_{x y}{ }^{2}},
$$

where $\sigma_{1}$ is the major principal stress, $\mathrm{MPa} ; \sigma_{3}$ is the minor principal stress, $\mathrm{MPa}$.

If the normal stress is compressive stress, the Mohr-Coulomb yield criterion is used as the criterion for the fracture of the KS. When $f_{s}<0$, it indicates that shear yield occurs in the KS. According to the stress sign conventions of elasticity, the modified equation of the Mohr-Coulomb yield criterion is as follows [28]:

$$
f_{s}=\sigma_{3}-\sigma_{1} \frac{1+\sin \varphi}{1-\sin \varphi}+2 c \sqrt{\frac{1+\sin \varphi}{1-\sin \varphi}},
$$

where $\varphi$ is the internal friction angle of the KS, ${ }^{\circ} ; c$ is the cohesion of the KS, MPa.

If the normal stress is tensile stress, the difference between the major principal stress and the tensile strength of the KS is used as the criterion for the fracture of the KS. When $f_{t}>0$, it indicates that tension yield occurs in the KS. The relationship between major principal stress and tensile strength is as follows:

$$
f_{t}=\sigma_{1}-\sigma_{t},
$$

where $\sigma_{t}$ is the tensile strength of the KS, MPa; $\sigma_{t}=(2 c \cos \varphi /(1+\sin \varphi))$.

\section{The Fracture Mechanism of the KS}

Considering two KS in the overlying strata as an example, the stress distribution law and fracture mechanism of the IKS under elastic foundation clamped boundary are analyzed. The width of the elastic foundation zone is $100 \mathrm{~m}$, and the grid spacing $h$ is $0.5 \mathrm{~m}$ to eliminate the boundary effect. The working face length is $200 \mathrm{~m}$, and the excavation length $30 \mathrm{~m}$. The IKS elastic modulus is $20 \mathrm{GPa}$, burial depth $100 \mathrm{~m}$, the thickness $5 \mathrm{~m}$, Poisson ratio 0.3 , load $q_{1}$ of $0.32 \mathrm{MPa}$, and foundation modulus $600 \mathrm{MN} / \mathrm{m}^{3}$. The PKS elastic modulus is $20 \mathrm{GPa}$, the thickness $10 \mathrm{~m}$, Poisson ratio 0.3 , load $q_{1}$ $0.3 \mathrm{MPa}$, and foundation modulus $300 \mathrm{MN} / \mathrm{m}^{3}$.

Obtain the KS's deflection according to the above difference method, and then draw the contour of the stress distribution of the KS according to equation (14). Figure 3 show the contour maps of the normal stress and shear stress on the upper surface of the KS's $x y$-plane. Figure 3(d) is the contour map of the normal stress $\sigma_{x}$ on the $x z$ section in the center of the KS. Figure 3(e) is the contour map of the normal stress $\sigma_{y}$ of the $y z$ section in the KS center. From equation (13), it can be seen that the stresses $\sigma_{x}$ and $\sigma_{y}$ of the corresponding points on the upper and lower surfaces of the $\mathrm{KS}$ are equal in value and opposite in direction. The stress range of the KS is larger than the mining area.

The KS above the goaf is subjected to compressive stress on the upper surface and tensile stress on the lower surface. The normal stress in the $x$-direction increases gradually from the center of the goaf to the surrounding coal walls. The normal stress in the $y$-direction decreases gradually from the center of the goaf to the surrounding coal walls. The KS above the elastic foundation zone is subjected to tensile stress on the upper surface and compressive stress on the lower surface. The normal stress value increases first and then decreases from the surrounding coal wall outward. It can be seen from the shear stress $\tau_{x y}$ contour map that, except for the four right angle ranges of the mining area, the shear stresses of the upper and lower surface of the KS are all zero.

According to the principal stress equation (15), when the shear stress is zero, the principal stress is equal to the normal stress. The normal stress on the center of the KS's upper and lower surface above the goaf and the center of the KS's upper and lower surface above the elastic foundation zone close to the coal wall around the goaf is the principal stress. According to $\sigma_{z}$ in equation (13), the KS's load above the goaf gradually decreases with $z$. As shown in Figure 2, the load of the KS above the elastic foundation zone includes two parts: the transfer load of the KS above the goaf and the original rock stress. $\sigma_{z}$ is perpendicular to $\sigma_{x}$ and $\sigma_{y}$. It can be seen that $\sigma_{z}$ is also the principal stress. As shown in Figure 2, the upper surface of the KS above the goaf is a triaxial compression state, and the lower surface is a biaxial tension state. The KS's upper surface above the elastic foundation zone close to the coal wall around the goaf is in a state of triaxial stress, which is tension in the horizontal direction and compression in the vertical direction, and the lower surface is in the state of triaxial compression. The tensile capacity of the rock material is far less than the compressive capacity. The center of the lower surface of the KS above the goaf and the upper surface of the KS above the elastic foundation zone near the coal wall fracture first are shown as the green and purple areas in Figure 4.

According to equation (16), draw the contour lines of the Mohr-Coulomb yield criterion, where the cohesion $c$ is $4 \mathrm{MPa}$ and the internal friction angle $\varphi$ is $39^{\circ}$, as shown in Figure 5. The principal tensile stress $\sigma_{1}$ in the horizontal direction outward along the surrounding coal walls of the KS presents a parabolic distribution characteristic. The principal stress $\sigma_{3}$ in the vertical direction is monotonously decreasing. Combined with the distribution law of $f_{s}$ in Figure 5 , the tensile stress increases, the compressive stress decreases, and $f_{s}$ gradually decreases. The tensile stress decreases, the compressive stress decreases, and $f_{s}$ gradually 


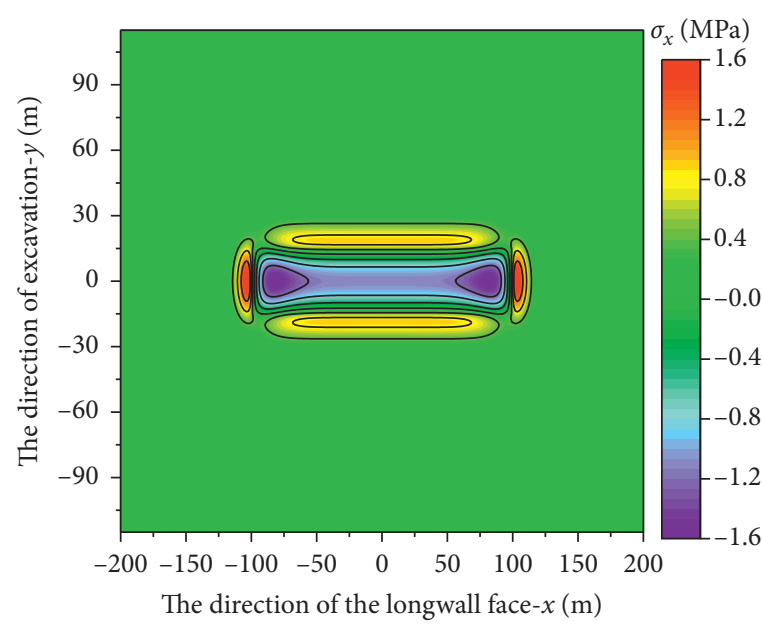

(a)

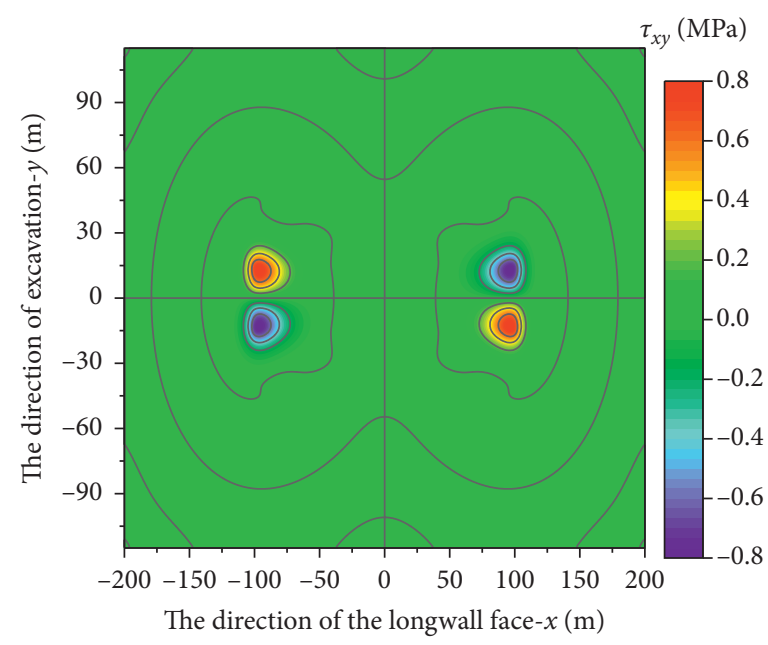

(c)

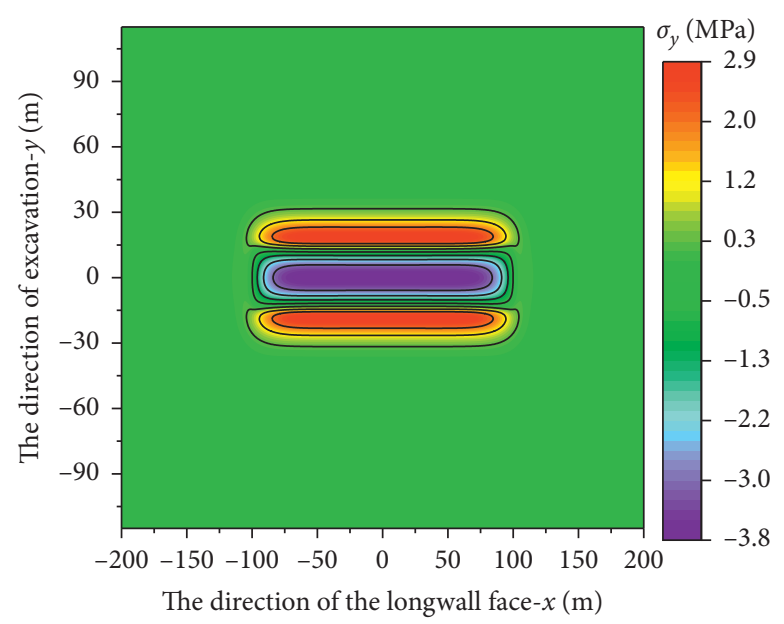

(b)

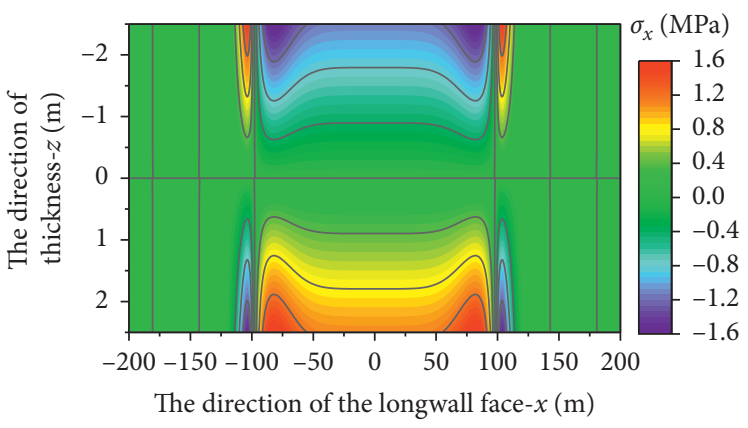

(d)

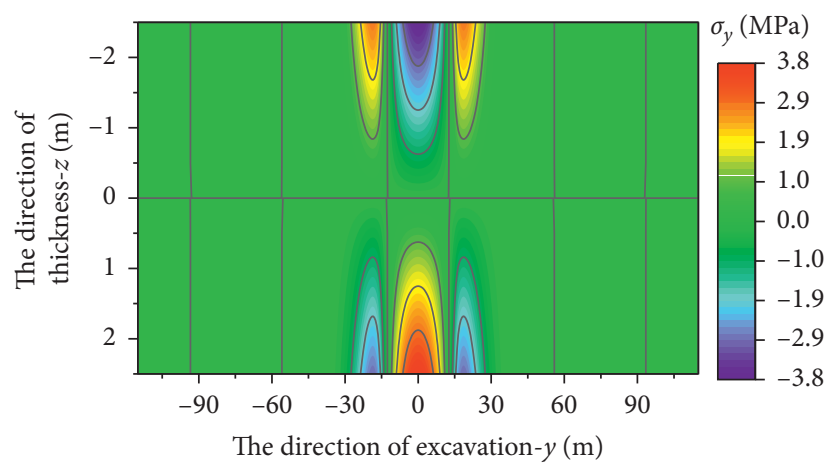

(e)

Figure 3: The contour maps of stress distribution of KS: (a) normal stress $\sigma_{x}$ on the upper surface of KS; (b) normal stress $\sigma_{y}$ on the upper surface of KS; (c) shear stress $\tau_{x y}$ on the upper surface of KS; (d) normal stress $\sigma_{x}$ on the section of KS; (e) normal stress $\sigma_{y}$ on the section of KS.

increases. The position where the tensile stress of the KS is maximum and $f_{s}$ is minimum is prone to shear fracture. When the normal stress of the KS is tensile stress, the maximum tensile stress position is prone to tensile fracture.

As shown in Figure 6, the extension direction of the tensile fracture in the center of the lower surface of the KS above the goaf is parallel to the working face. When the fracture extends to the coal walls on both sides, the extension direction turns to the right angle area. The expansion direction of the shear fracture in the center of the upper surface of the KS above the elastic foundation zone around the goaf is parallel to the coal wall. It links up when the 


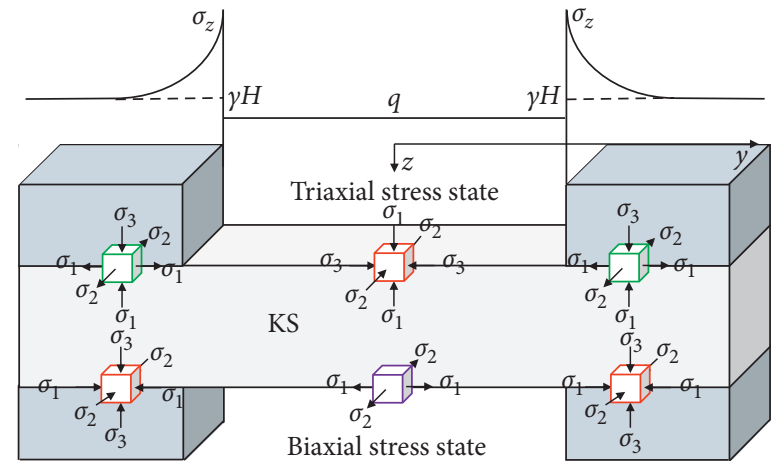

FIgURe 4: Principal stress distribution characteristics of KS.

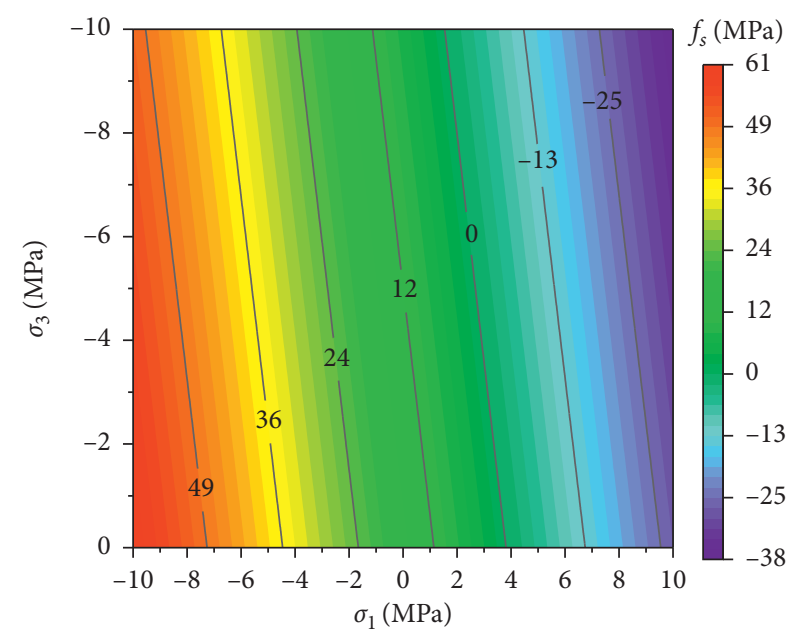

Figure 5: The contour of the Mohr-Coulomb yield criterion.

fracture extends to the right angle area. The distance from the maximum tensile stress position of the KS above the elastic foundation zone to the coal wall is defined as the advanced influence distance (AID). $L_{v}$ symbolizes the AID in the vertical direction of the longwall face. $L_{p}$ symbolizes the AID in the long wall's parallel direction. When the KS fractures, the AID is the advanced fracture distance (AFD).

\section{Analysis of Influencing Factors of the Fracture of KS}

There is a single factor analysis method to study the influence of geological and mining conditions on the fracture of the KS. The calculation parameters are the same as those in Section 3. According to equations (4)-(7), the factors affecting the fracture of the KS included the excavation length, the foundation modulus, the flexural rigidity of the KS, the load of the KS, and the advanced load of the KS. The following is the study of the impact on the KS's fracture and analysis of the fracture law of the KS.

4.1. Excavation Length L. As the working face of the longwall is excavated forward, the principal stress of the KS increases.
However, the stress increase rate at different positions is different, so the fracture sequence is different. Figure $7(a)$ is the result of the yield criterion changing with the excavation length. $f_{s v}$ symbolizes the result of yield criterion in the middle of the long side advance coal wall area of KS. $f_{s p}$ symbolizes the result of yield criterion in the middle of the short side advance coal wall area of KS. $f_{t}$ symbolizes the result of yield criterion in the center of KS.

With the increase of excavation length, $f_{s v}$ in the middle of the long side advance coal wall area of the KS and $f_{s p}$ in the middle of the short side advance coal wall area of the KS decrease, and $f_{t}$ in the center of the KS increases. The decrease of $f_{s v}$ is greater than that of $f_{s p}$. According to equations (16)(17), when $f_{s}<0, f_{t}>0$, it means that the KS is fractural. When $L<L_{a}, f_{s v}>0, f_{s p}>0$, and $f_{t}<0$, indicating that the KS does not fracture. When $L_{a}<L<L_{b}, f_{s v}<0, f_{s p}>0$, and $f_{t}>0$, indicating that the middle of the long side advance coal wall area of the $\mathrm{KS}$ and the center of the KS fracture. When $L>L_{b}, f_{s v}<0, f_{s p}$ $<0$, and $f_{t}>0$, indicating that the surrounding walls and the central area of the KS fracture.

Figure 7(b) shows the curves of the AID $L_{v}$ and $L_{p}$ changing with excavation length. With the increase of excavation length, $L_{v}$ in the middle of the long side advance coal wall area of the KS and $L_{p}$ in the middle of the short side advance coal wall area of the KS decrease. The decrease of $L_{v}$ is greater than that of $L_{p}$.

4.2. Foundation Modulusk. The foundation modulus has the effect of restraining the KS's deformation and can affect the KS's stress distribution. Figure 8(a) shows the curve of $f$ changing with the foundation modulus. With the increase of foundation modulus, $f_{s v}$ in the middle of the long side advance coal wall area of the KS, $f_{s p}$ in the middle of the short side advance coal wall area of the KS, and $f_{t}$ in the center of the KS decrease. The decrease of $f_{s v}$ is greater than that of $f_{s p}$. When $k<k_{a}, f_{s v}>0, f_{s p}>0$, and $f_{t}>0$, indicating that the center of the KS fracture. When $k_{a}<k<k_{b}, f_{s v}>0, f_{s p}>0$, and $f_{t}<0$, indicating that the KS does not fracture. When $k>k_{b}$, $f_{s v}<0, f_{s p}>0$, and $f_{t}<0$, indicating that the middle of the long side advance coal wall area of the KS fracture.

Figure 8 (b) shows the curve of the AID $L_{v}$ changing with foundation modulus. With the increase of foundation modulus, the boundary support capacity increases. The advanced influence range is transferred to the goaf, and $L_{v}$ in the middle of the long side advance coal wall area of the KS is gradually reduced. The law of $L_{p}$ in the middle of the short side advance coal wall area of the KS is the same as that of $L_{v}$.

4.3. Flexural Rigidity of the KS D. The flexural rigidity characterizes the ability of the KS to resist flexural deformation and can affect the KS's stress distribution. Figure 9(a) shows the curve of $f$ changing with the flexural rigidity of the $\mathrm{KS}$. With the increase of flexural rigidity of the KS, $f_{s v}$ in the middle of the long side advance coal wall area of the KS, $f_{s p}$ in the middle of the short side advance coal wall area of the KS, and $f_{t}$ in the center of the KS increase. When $D<D_{a}, f_{s v}<0$, $f_{s p}>0$, and $f_{t}<0$, indicating that the middle of the long side advance coal wall area of the KS fractures. When 


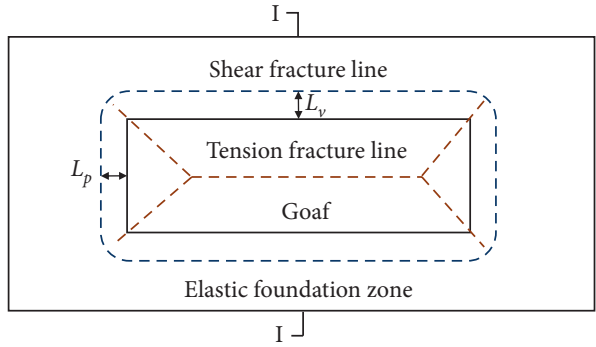

(a)

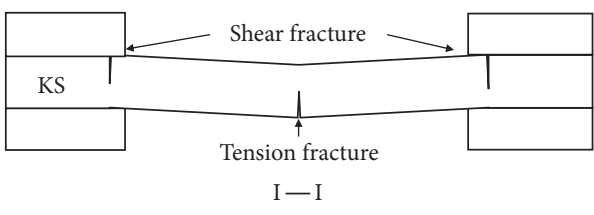

(b)

FIgURE 6: The fracture characteristics of KS.

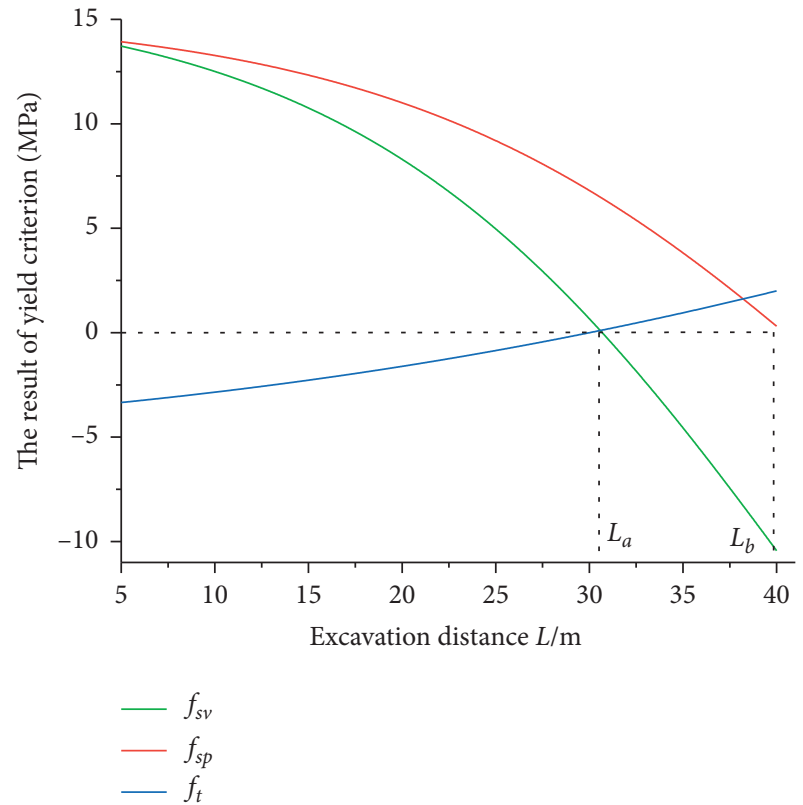

(a)

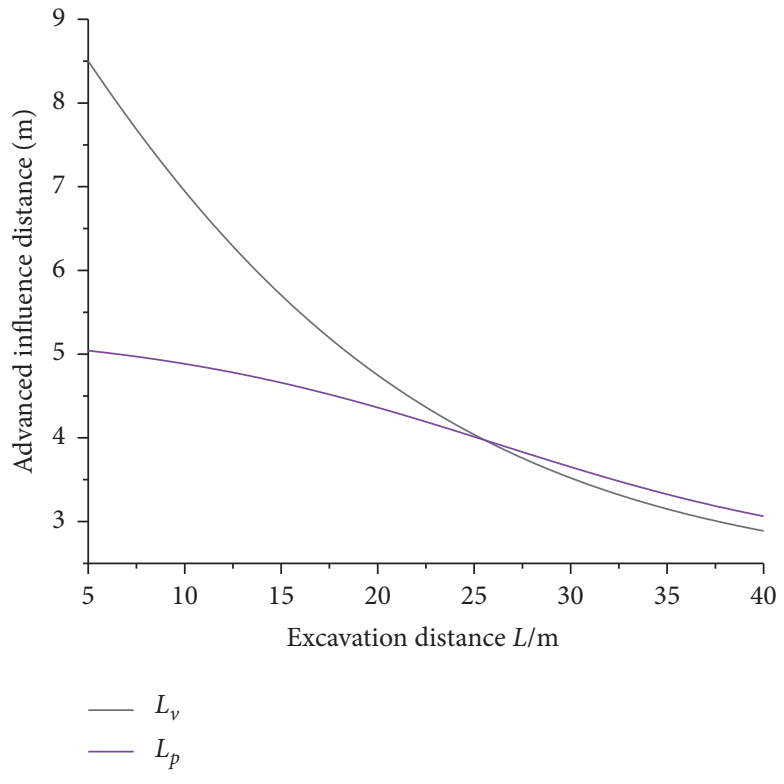

(b)

Figure 7: The influence of excavation length on the fracture of KS: (a) the result of yield criterion changing with excavation length; (b) the curve of AID changing with excavation length.

$D_{a}<D<D_{b}, f_{s v}>0, f_{s p}>0$, and $f_{t}<0$, indicating that the KS does not fracture. When $D>D_{b}, f_{s v}>0, f_{s p}>0$, and $f_{t}>0$, indicating that the center of the KS fractures.

Figure 9(b) shows the curve of the AID $L_{v}$ changing with flexural rigidity of the KS. With the increase of flexural rigidity, the flexural capacity of the KS increases. The advanced influence range transfers to the interior of the coal wall, and $L_{v}$ in the middle of the long side advance coal wall area of the KS gradually increases. The law of $L_{p}$ in the middle of the short side advance coal wall area of the KS is the same as that of $L_{v}$.

4.4. The Load of the KS $q_{1}$. The stress of the KS increases with the increase of $q_{1}$. Figure 10(a) shows the curve of $f$ changing with the load of the KS. With the increase of the KS's load, $f_{s v}$ in the middle of the long side advance coal wall area of the KS and $f_{s p}$ in the middle of the short side advance coal wall area of the KS decrease. $f_{t}$ in the center of the KS increases.
The decrease of $f_{s v}$ is greater than that of $f_{s p}$. When $q_{1}<q_{a}$, $f_{s v}>0, f_{s p}>0$, and $f_{t}<0$, indicating that the KS does not fracture. When $q_{a}<q_{1}<q_{b}, f_{s v}<0, f_{s p}>0$, and $f_{t}>0$, indicating that the middle of the long side advances the wall area of the KS and the center of the KS fracture. When $q_{1}>q_{b}$, $f_{s v}<0, f_{s p}<0$, and $f_{t}>0$, indicating that the surrounding walls and the center area of the KS fracture.

Figure 10(b) shows the curve of the AID $L_{v}$ changing with the load of the KS. The stress distribution range of the KS does not change with the increase of load $q_{1}$. The advanced influence range remains unchanged, and $L_{v}$ in the middle of the long side advance coal wall area of the KS remains unchanged. The law of $L_{p}$ in the middle of the short side advance coal wall area of the KS is the same as that of $L_{v}$.

4.5. The Advanced Load of the KS $q_{2}$. The stress of the KS increases with the increase of $q_{2}$. Figure 11(a) is the curve of $f$ 


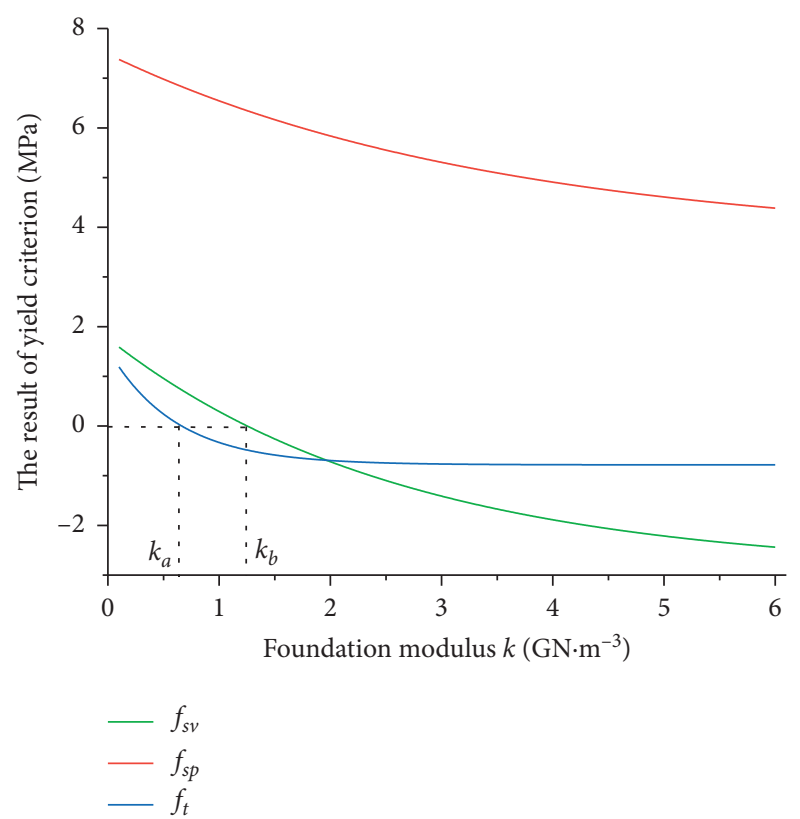

(a)

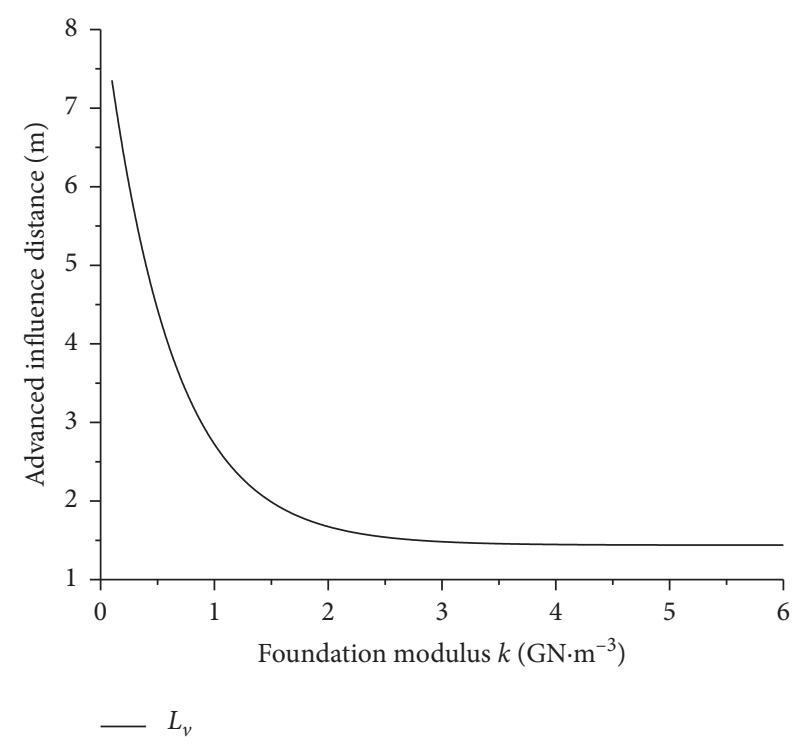

(b)

FIGURE 8: The influence of foundation modulus on the fracture of KS: (a) the result of yield criterion changing with foundation modulus; (b) the curve of $L_{v}$ changing with foundation modulus.

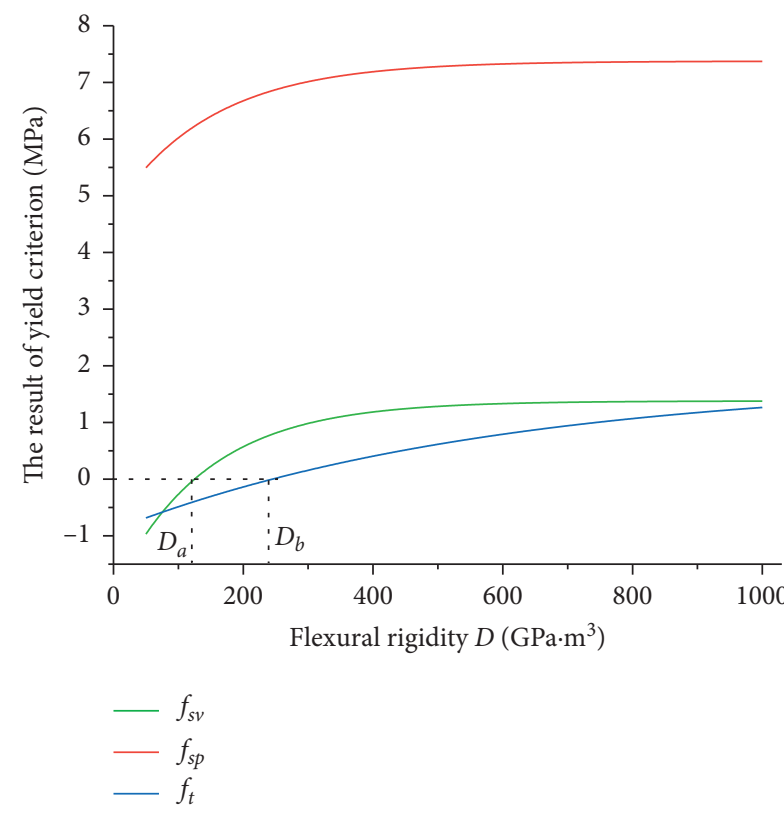

(a)

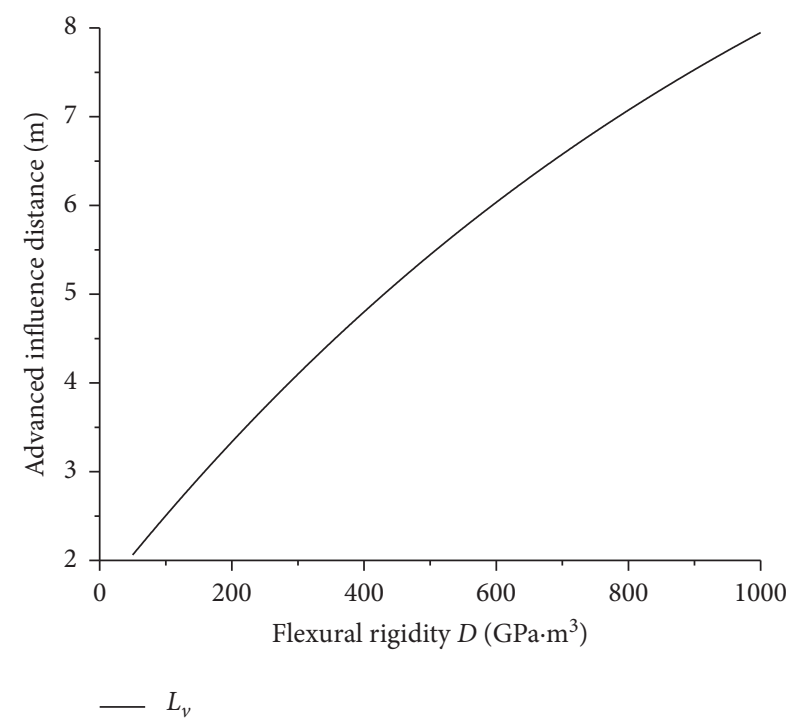

(b)

FIGURE 9: The influence of flexural rigidity on the fracture of KS: (a) the result of yield criterion changing with flexural rigidity; (b) the curve of $L_{v}$ changing with flexural rigidity.

changing with the advanced load of the KS. With the increase of the advanced load of the KS, $f_{s v}$ in the middle of the long side advance coal wall area of the KS and $f_{s p}$ in the middle of the short side advance coal wall area of the KS decrease, and $f_{t}$ in the center of the KS increases. The decrease of $f_{s v}$ is greater than that of $f_{s p}$. When $q_{2}<q_{a}, f_{s v}>0$, $f_{s p}>0$, and $f_{t}>0$, indicating that the center of the KS fractures. When $q_{2}>q_{b}, f_{s v}<0, f_{s p}<0$, and $f_{t}>0$, indicating that the middle of the long side advance coal wall area of the KS and the center of the KS fracture. 


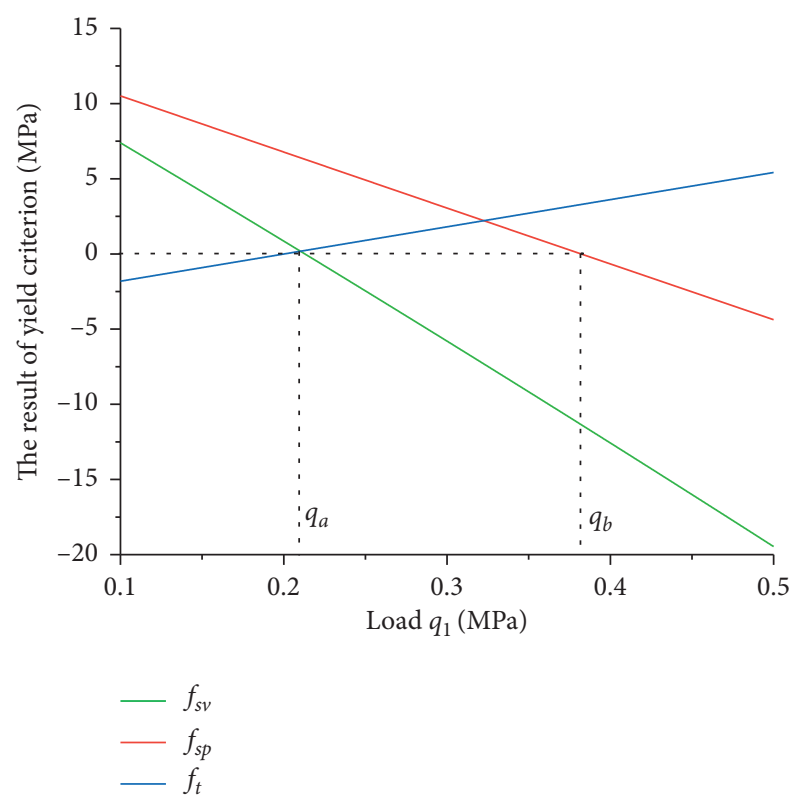

(a)

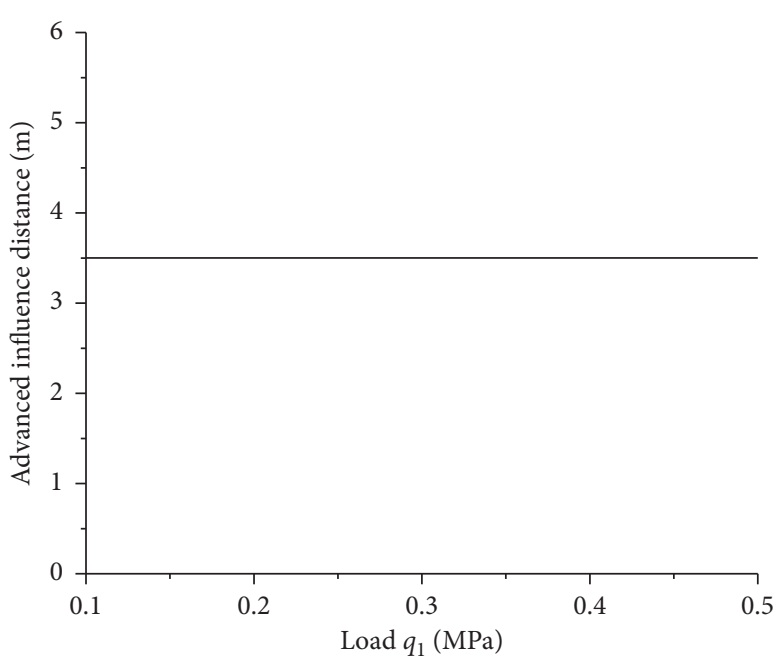

$-L_{v}$

FIgURE 10: The influence of $q_{1}$ on the fracture of KS: (a) the result of yield criterion changing with $q_{1}$; (b) the curve of $L_{v}$ changing with $q_{1}$.

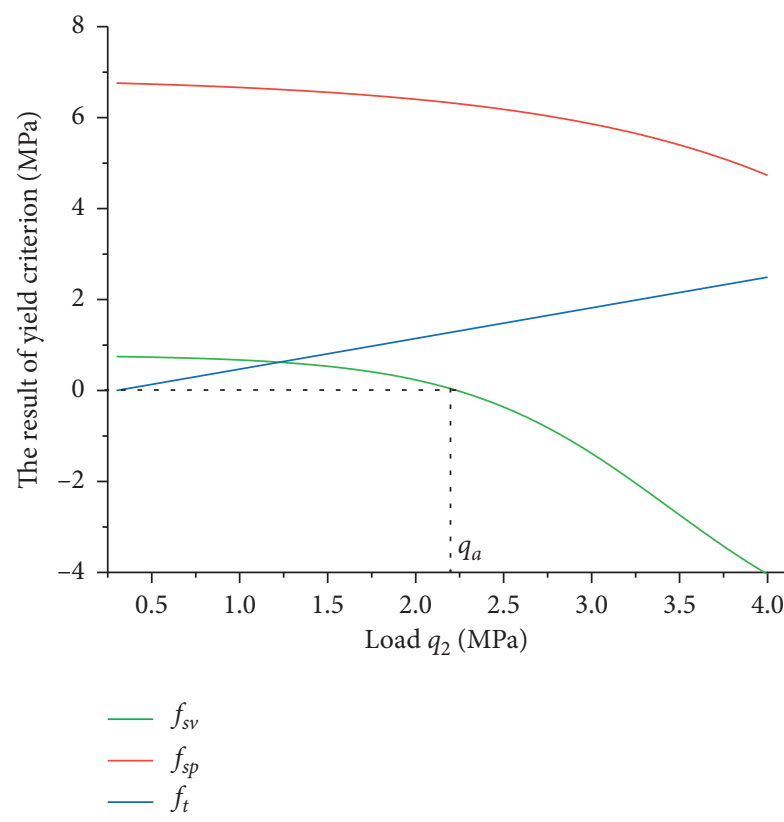

(a)

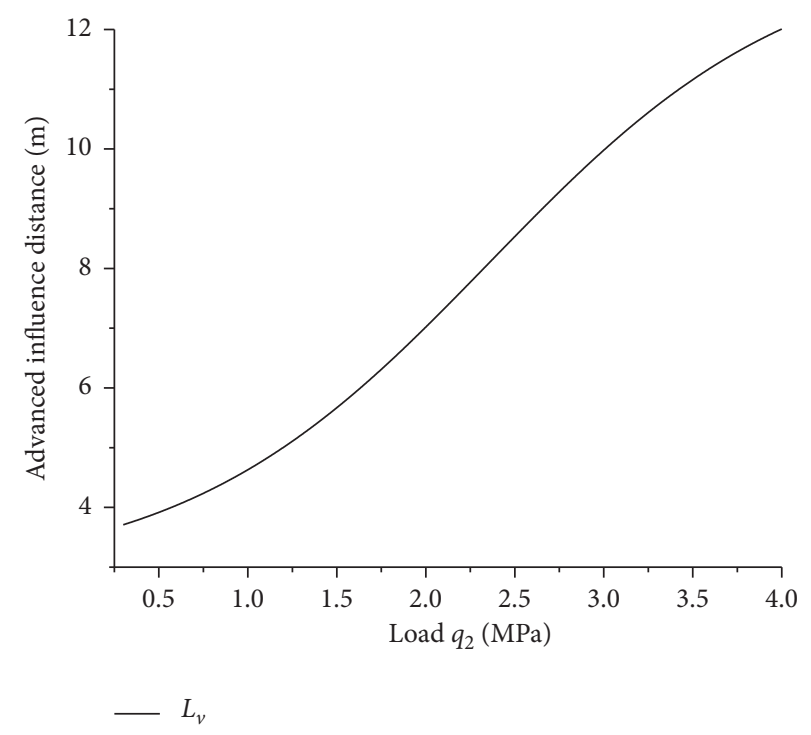

(b)

FIGURE 11: The influence of $q_{2}$ on the fracture of KS: (a) the result of yield criterion changing with $q_{2}$; (b) the curve of $L_{v}$ changing with $q_{2}$.

Figure 11(b) is the curve of the AID $L_{v}$ changing with the advanced load of the KS. With the increase of the advanced load, the advanced influence range transfers to the interior of the coal wall, and the $L_{v}$ in the middle of the long side advance coal wall area of the KS gradually increases. The law of $L_{p}$ in the middle of the short side advance coal wall area of the KS is the same as that of $L_{v}$.

\section{Numerical Simulation of the Fracture of the Overlying Strata}

5.1. Numerical Model. The numerical calculation model is established by Universal Distinct Element Code (UDEC) simulation software $[29,30]$. As shown in Figure 12, there are two groups of the KS in the model. The model has a size 


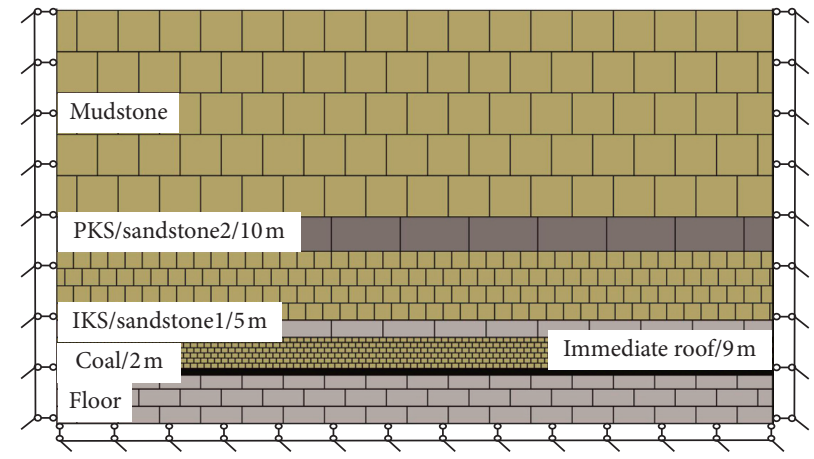

Figure 12: Numerical calculation model.

of $600 \mathrm{~m} \times 120 \mathrm{~m}$. The width of the coal pillar of $200 \mathrm{~m}$ is set to minimize the boundary effect. The horizontal stress is calculated by introducing Poisson's ratio. The boundaries of the model are both on the rollers to simulate the initial stress field.

The rock stratum's mesh size is $2 \mathrm{~m}$. Blocks adopt the Mohr-Coulomb constitutive model. Joints adopt the Coulomb-slip model. The mechanical parameters of the blocks and joints are shown in Tables 1 and 2 .

5.2. Analysis of Simulation Results. The longwall face excavation will form the goaf. The stress redistribution occurs in the overlying strata due to the loss of coal seam support. With the increase of the goaf, the rock strata stress exceeds its strength, and the rock strata will fracture and form a plastic zone. Figure 13 shows the distribution of principal stress and plastic zone of the overlying strata when the excavation length is $30 \mathrm{~m}$.

Figure 13(a) is the distribution of minor principal stress in the overlying strata. Arrange the measuring points on the upper surface of IKS. Figure 13(c) is the distribution of minor principal stress of the upper surface of IKS. The minor principal stress of IKS is compressive stress. The absolute value of minor principal stress in the IKS above the goaf decreases gradually from the upper surface to the lower surface. The absolute value of minor principal stress in the IKS above the elastic foundation zone increases gradually from the upper surface to the lower surface. The maximum absolute value of minor principal stress is located at the lower surface of the IKS above the elastic foundation zone close to the coal wall. There is advanced compressive stress of the IKS in the elastic foundation zone, as shown in Figure 13(c).

Figure 13(b) is the distribution of major principal stress in the overlying strata. Figure $13(\mathrm{~d})$ is the distribution of major principal stress of the upper surface of IKS. The major principal stress of the IKS above the goaf increases gradually from the upper surface to the lower surface. The major principal stress of the IKS above the elastic foundation zone decreases gradually from the upper surface to the lower surface. The maximum principal stress position is located in the IKS above the elastic foundation zone close to the coal wall, and the upper surface is tensile stress, and the lower surface is compressive stress. There is advanced tensile stress of the IKS in the elastic foundation zone, as shown in Figure 13(d). The stress state of the KS at different positions is the same as Figure 2 in Section 3, which proves the correctness of the theoretical analysis.

Figure $13(\mathrm{e})$ is the plastic zone distribution of the overlying strata, The tensile stress on the lower surface of the IKS above the goaf does not exceed its tensile strength, so there is no tensile fracture. The upper surface of the IKS above the elastic foundation zone close to the coal wall is subjected to tensile stress and compressive stress. $f_{s}$ is less than zero by the Mohr-Coulomb yield criterion, so there is a shear fracture. As shown in Figure 13(e), the fracture position of the IKS is about $7 \mathrm{~m}$ in advance coal wall. The fracture range of weak strata controlled by IKS is less than that of KS. The fracture range of the overlying strata is similar to the saddle-shaped distribution.

Figure 14 shows the distribution of principal stress and plastic zone of the overlying strata when the excavation length is $45 \mathrm{~m}$. With the increase of excavation length, the advanced stress value and influence range of the IKS increase, as shown in Figures 14(a) and 14(b). As shown in Figure 14(c), due to the increase of the IKS's principal stress above the elastic foundation zone, the fracture range extends to the inside of the coal wall. The shear fracture distance increases to $11 \mathrm{~m}$. Due to the tensile stress on the lower surface of the KS above the goaf exceeding its tensile strength, tensile fracture occurs.

The influence of foundation modulus on IKS fracture is verified by changing the thickness of the immediate roof. With the increase of the thickness of the immediate roof, the foundation modulus of IKS decreases. The AFD of IKS increases with the decrease of foundation modulus, as shown in Figure 15(a). The foundation modulus also affects the displacement of IKS, as shown in Figure 15(b). With the decrease of foundation modulus, the displacement value of IKS increases. The IKS above the elastic foundation zone produces obvious compressional deformation, which verifies the theoretical model of the clamped boundary. 
TABLe 1: Physicomechanical parameters of coal and rocks in numerical simulation.

\begin{tabular}{lcccccc}
\hline Lithology & $\begin{array}{c}\text { Density }(\mathrm{kg} / \\
\left.\mathrm{m}^{3}\right)\end{array}$ & $\begin{array}{c}\text { Elastic modulus } \\
(\mathrm{GPa})\end{array}$ & $\begin{array}{c}\text { Poisson's ratio } \\
\mu\end{array}$ & $\begin{array}{c}\text { Cohesion } c^{\mathrm{b}} \\
(\mathrm{MPa})\end{array}$ & $\begin{array}{c}\text { Internal friction angle } \varphi^{\mathrm{b}} \\
\left({ }^{\circ}\right)\end{array}$ & $\begin{array}{c}\text { Tensile strength } \sigma_{\mathrm{t}}^{\mathrm{b}} \\
(\mathrm{MPa})\end{array}$ \\
\hline Sandstone1 & 2700 & 20 & 0.30 & 4.0 & 39 & 3.40 \\
Sandstone2 & 2750 & 25 & 0.28 & 8.0 & 40 & 7.80 \\
Mudstone & 2400 & 4 & 0.33 & 1.0 & 33 & 1.08 \\
Coal & 1800 & 2.5 & 0.35 & 0.8 & 25 & 1.02 \\
\hline
\end{tabular}

TABLE 2: Physicomechanical parameters of interlayer joints in numerical simulation.

\begin{tabular}{lccc}
\hline Lithology & Normal stiffness kn $(\mathrm{GPa})$ & Shear stiffness ks $(\mathrm{GPa})$ & Internal friction angle $\varphi^{\mathrm{j}}\left(^{\circ}\right)$ \\
\hline Sandstone1 & 67.3 & 26.92 & 15 \\
Sandstone2 & 84.1 & 33.65 & 15 \\
Mudstone & 29.6 & 11.84 & 15 \\
Coal & 20.1 & 8.04 & 15 \\
\hline
\end{tabular}

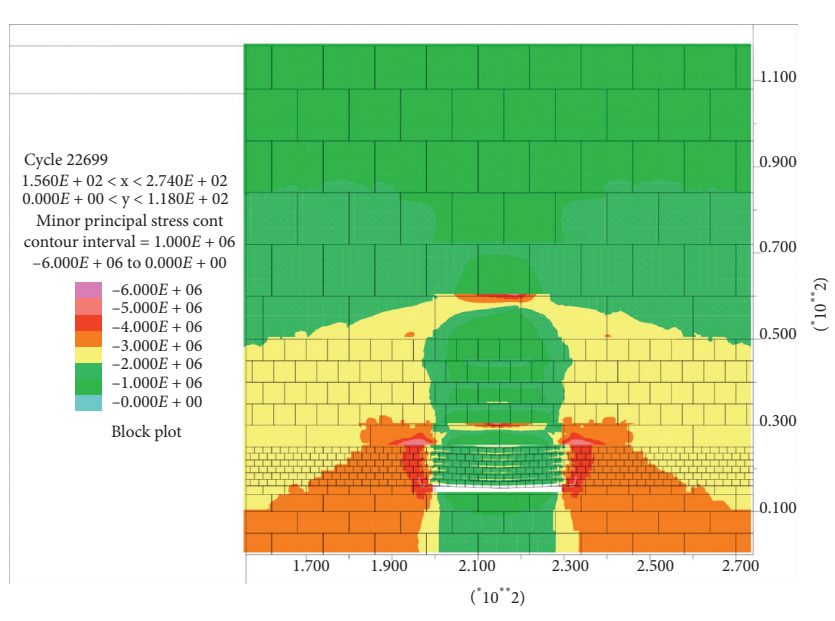

(a)

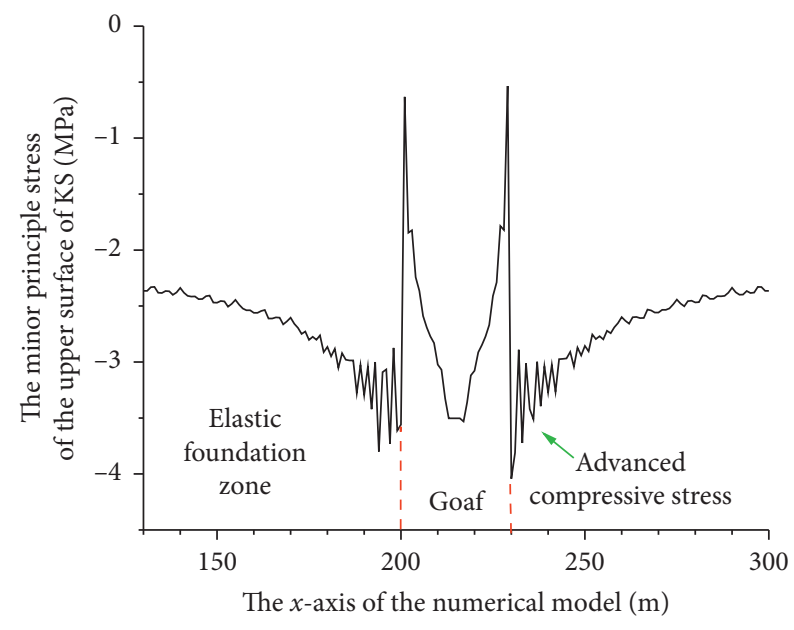

(c)

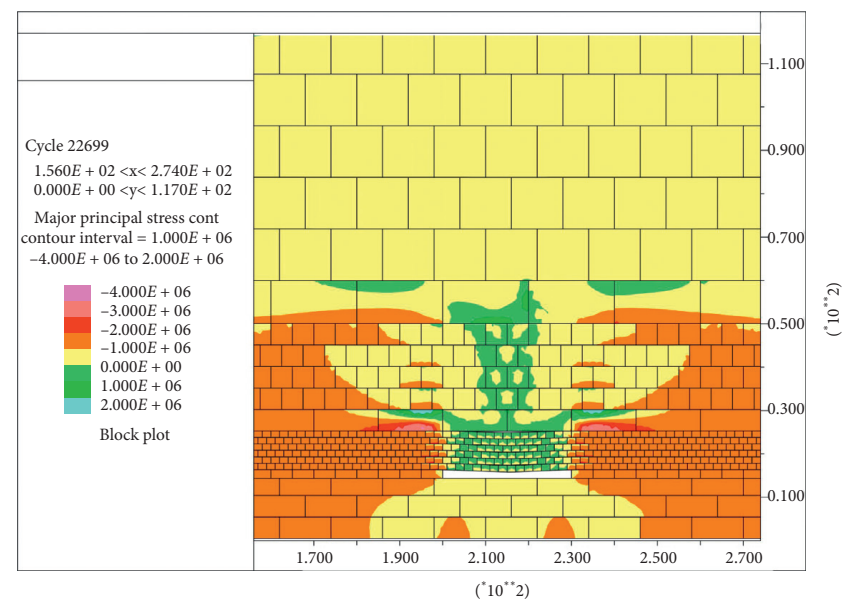

(b)

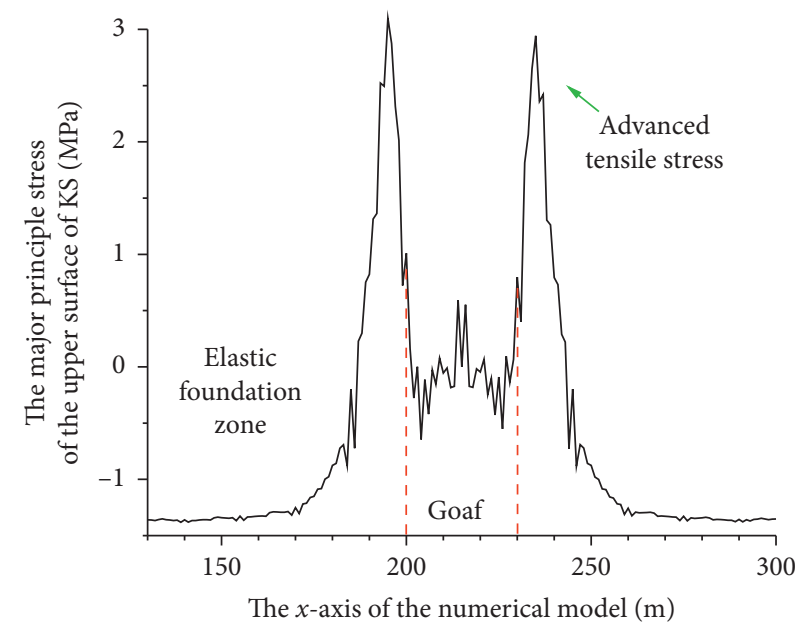

(d)

Figure 13: Continued. 


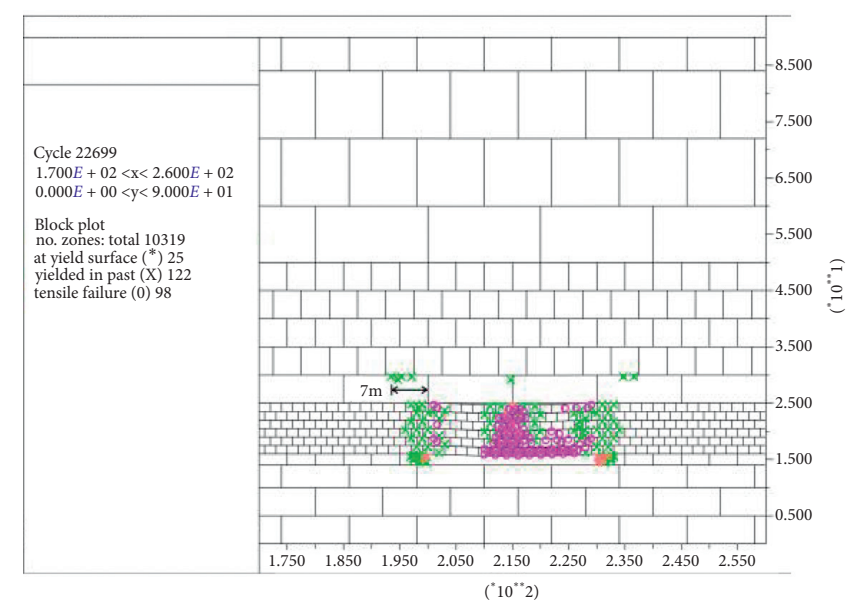

(e)

FIgURE 13: The distribution of principal stress and plastic zone when the excavation length is $30 \mathrm{~m}$. (a) The distribution of minor principal stress; (b) the distribution of major principal stress; (c) the distribution of minor principal stress of the upper surface of IKS; (d) the distribution of major principal stress of the upper surface of IKS; (e) the plastic zone distribution of the overlying strata.

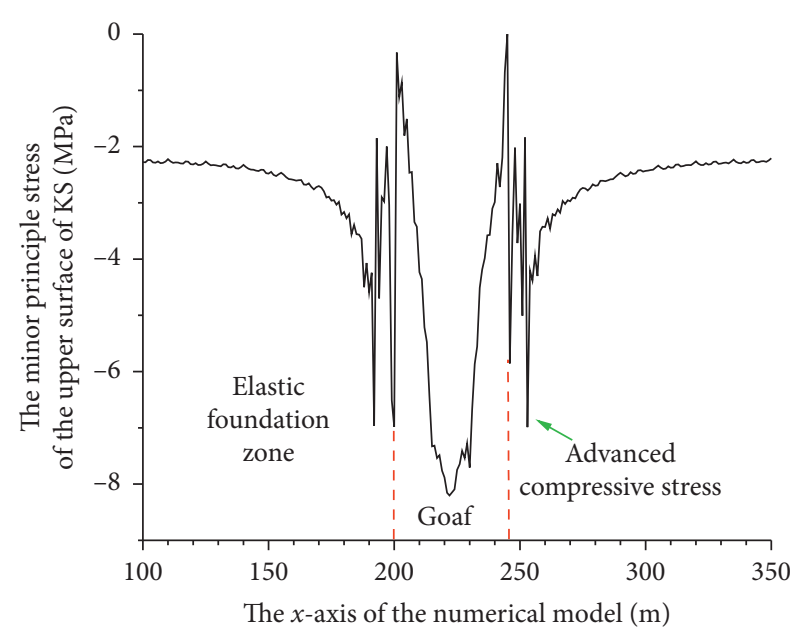

(a)

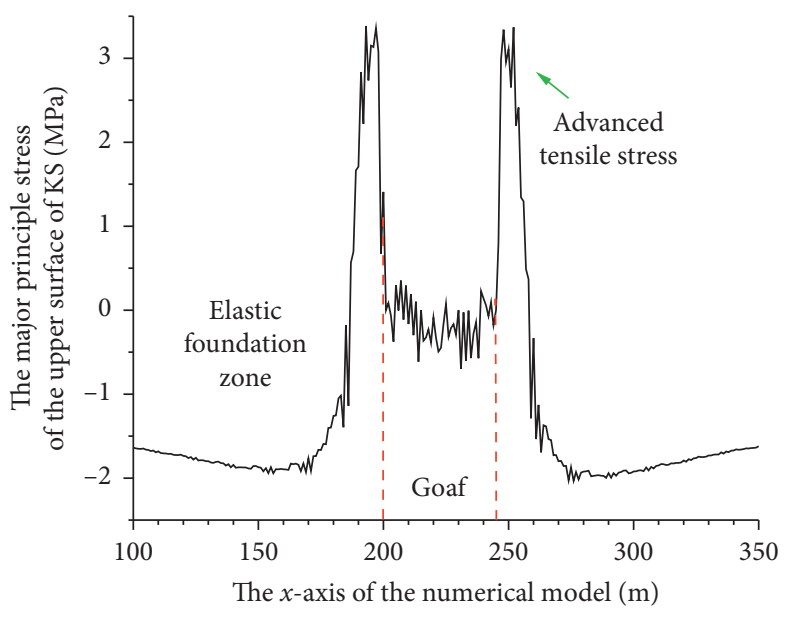

(b)

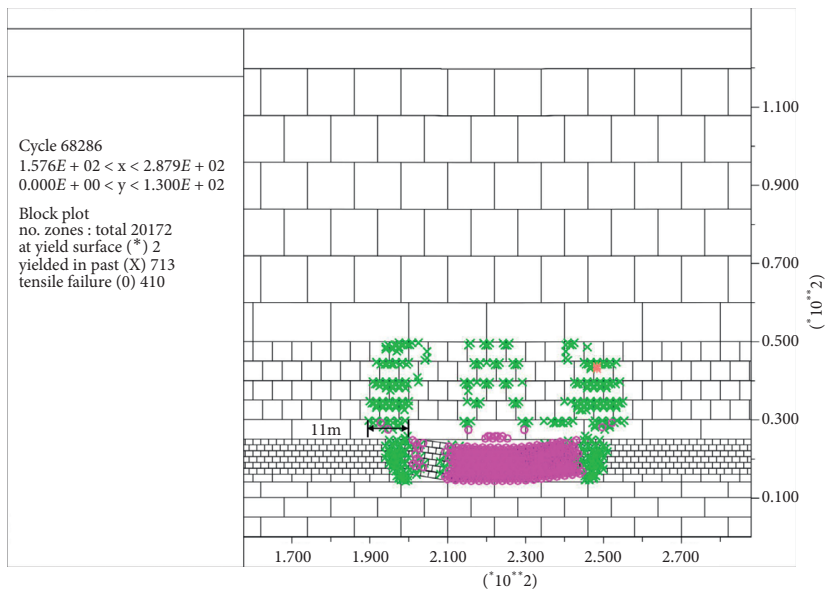

(c)

Figure 14: The distribution of principal stress and plastic zone when the excavation length is $45 \mathrm{~m}$. (a) The distribution of minor principal stress of the upper surface of IKS; (b) the distribution of major principal stress of the upper surface of IKS; (c) the plastic zone distribution of the overlying strata. 


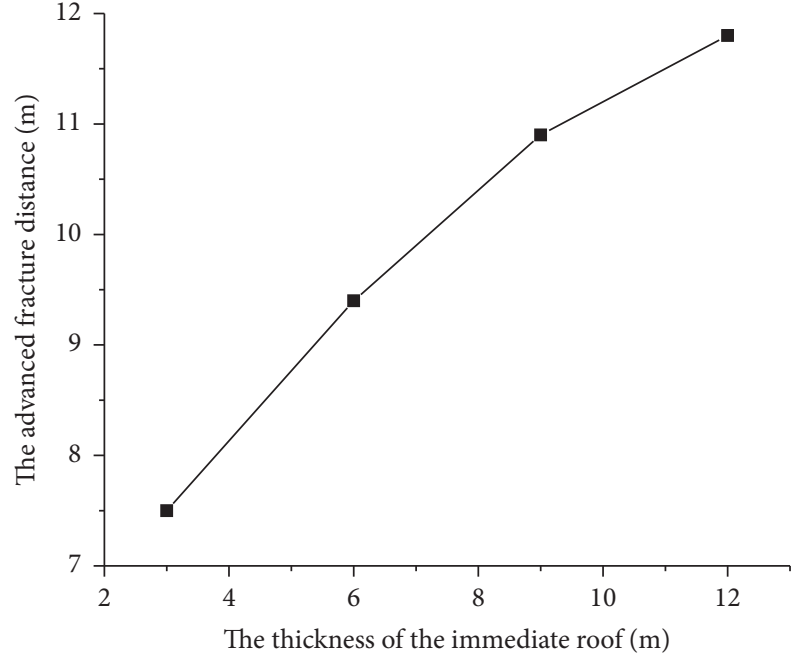

(a)

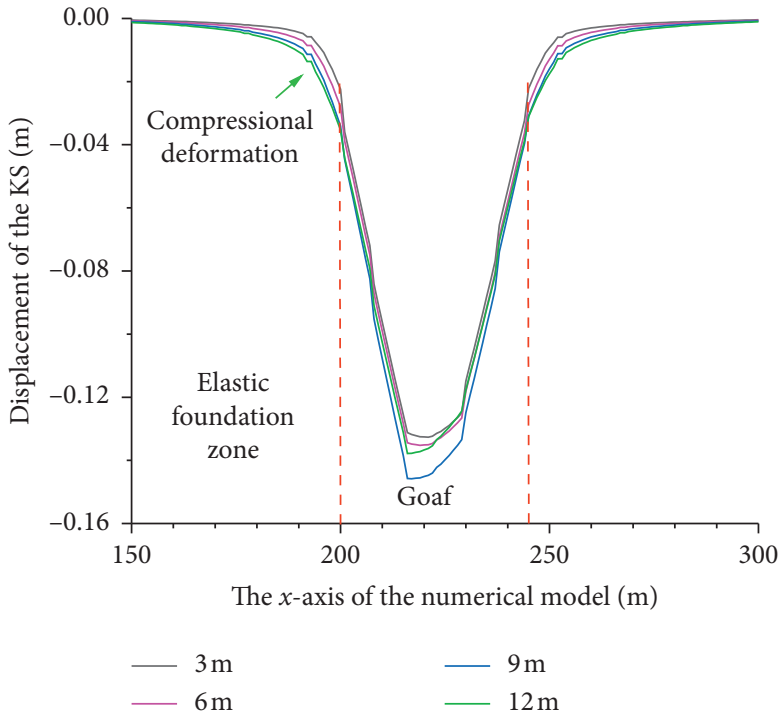

(b)

FIGURE 15: The influence of foundation modulus on the IKS: (a) the influence of foundation modulus on the advanced fracture of IKS; (b) the influence of foundation modulus on the displacement of IKS.

\section{Discussion and Conclusions}

The overlying strata fracture caused by mining has a significant influence on safety production. To reveal the fracture mechanism of the overlying strata, we established a mechanical model that is more in line with engineering reality based on the theory of elasticity. Combined with the Mohr-Coulomb yield criterion, we comprehensively explained the fracture process of the overlying strata. However, we only studied the first fracture mechanism of the KS and its influence on the fracture morphology of the overlying strata. The complex model that considers more influencing factors such as tectonic joint and sloping strata should be further verified in future research. The conclusions are as follows:

(1) The fracture mechanisms of the KS varied depending on the position under longwall mining. The position at the KS upper surface above the elastic foundation zone presented the characteristics of shear fracture. The position at the lower surface of the KS above the goaf presented the characteristics of tensile fracture. The fracture range of the overlying strata above the goaf is greater than the mining range.

(2) Different influencing factors lead to different KS fracture sequences. With the increase of the excavation length and the load of the KS, the fracture sequence of the KS is that the center and the long side fracture first, and then the short side fractures. With the increase of the flexural rigidity of the KS, the fracture sequence is long side-center-short side. With the increase of the foundation modulus and the advanced load of the KS, the fracture sequence is the center-long side-short side.

(3) With the increase of the KS flexural rigidity and advanced load, the advanced influence distance (AID) increases. With the increase of the foundation modulus and excavation length, the advanced influence distance (AID) decreases. The advanced influence distance (AID) is not affected by the KS load.

(4) The numerical simulation results show that with the longwall working face excavation, the range of the overlying strata fracture expands, and the fracture morphology presents saddle-shaped distribution characteristics. The advanced fracture distance (AID) of the KS decreases with the decrease of the immediate roof thickness. The simulation results are consistent with the theoretical analysis.

\section{Data Availability}

The data used to support the findings of this study are available from the corresponding author upon request.

\section{Conflicts of Interest}

The authors declare that they have no conflicts of interest.

\section{Acknowledgments}

This work was supported by the Heilongiiang Natural Science Fund for Excellent Young Scholars Project (YQ2019E033).

\section{References}

[1] S. S. Peng, Longwall Mining, CRC Press/Balkema, London, UK, 3rd edition, 2019.

[2] G.-A. Zhu, L.-M. Dou, A.-Y. Cao et al., "Assessment and analysis of strata movement with special reference to rock burst mechanism in island longwall panel," Journal of Central South University, vol. 24, no. 12, pp. 2951-2960, 2017. 
[3] B. Ghabraie, G. Ren, and J. V. Smith, "Characterising the multi-seam subsidence due to varying mining configuration, insights from physical modelling," International Journal of Rock Mechanics and Mining Sciences (Oxford, England: 1997), vol. 93, pp. 269-279, 2017.

[4] D. Xu, S. Peng, S. Xiang, and Y. He, "A novel caving model of overburden strata movement induced by coal mining," Energies, vol. 10, no. 4, p. 476, 2017.

[5] K. Wu, G.-L. Cheng, and D.-W. Zhou, "Experimental research on dynamic movement in strata overlying coal mines using similar material modeling," Arabian Journal of Geosciences, vol. 8, no. 9, pp. 6521-6534, 2015.

[6] H. Han, J. Xu, X. Wang et al., "Surface subsidence prediction method for coal mines with ultrathick and hard stratum," Advances in Civil Engineering, vol. 2019, Article ID 3714381, 15 pages, 2019.

[7] C. He, J. Xu, and D. Wang, "Subsidence prediction of overburden strata and surface based on the Voussoir beam structure theory," Advances in Civil Engineering, vol. 2018, Article ID 2606108, 13 pages, 2018.

[8] Y. Zhou, J. Zuo, C. Hu, G. Liu, Y. Shi, and H. Liu, "Strata movement model of filling coal mining based on two-parameter elastic foundation," Geotechnical and Geological Engineering, vol. 38, no. 4, pp. 3631-3641, 2020.

[9] G. K. Ghosh and C. Sivakumar, "Application of underground microseismic monitoring for ground failure and secure longwall coal mining operation: a case study in an Indian mine," Journal of Applied Geophysics, vol. 150, pp. 21-39, 2018.

[10] W. Guo, G. Zhao, G. Luo et al., "A new method of predicting the height of the fractured water-conducting zone due to high-intensity longwall coal mining in China," Rock Mechanics and Rock Engineering, vol. 8, no. 52, pp. 2789-2802, 2019.

[11] W. Guo, G. Zhao, G. Lou et al., "Height of fractured zone inside overlying strata under high-intensity mining in China," International Journal of Mining Science and Technology, vol. 29, no. 1, pp. 45-49, 2018.

[12] Y. Sun, J. Zuo, M. Karakus et al., "Investigation of movement and damage of integral overburden during shallow coal seam mining," International Journal of Rock Mechanics and Mining Sciences (Oxford, England: 1997), vol. 117, pp. 63-75, 2019.

[13] Y. Li, T.-H. Yang, H.-L. Liu et al., "Real-time microseismic monitoring and its characteristic analysis in working face with high-intensity mining," Journal of Applied Geophysics, vol. 132, pp. 152-163, 2016.

[14] B. Yu, J. Zhao, and H. Xiao, "Case study on overburden fracturing during longwall top coal caving using microseismic monitoring," Rock Mechanics and Rock Engineering, vol. 50, no. 2, pp. 507-511, 2017.

[15] H. He, L. Dou, A. Cao et al., "Mechanisms of mining seismicity under large scale exploitation with multikey strata," Shock and vibration, vol. 2015, Article ID 313069, 9 pages, 2015.

[16] S. Qin, J. Cheng, and S. Zhu, "The application and prospect of microseismic technique in coalmine," Procedia Environmental Sciences, vol. 12, pp. 218-224, 2012.

[17] X. Shi, X. Zhang, and F. Jiang, "A case study of fracture law and stress distribution characteristics of surrounding rock of working face in deep mines," Geotechnical and Geological Engineering, vol. 37, no. 4, pp. 2935-2948, 2019.

[18] G. Cheng, T. Ma, C. Tang, H. Liu, and S. Wang, "A zoning model for coal mining-induced strata movement based on microseismic monitoring," International Journal of Rock Mechanics and Mining Sciences, vol. 94, pp. 123-138, 2017.
[19] S. S. Peng, Advances in Coal Mine Ground Control, Woodhead, Duxford, UK, 2017.

[20] Y. Xu, L. Ma, and Y. Yu, "Water preservation and conservation above coal mines using an innovative approach: a case study," Energies, vol. 13, no. 11, p. 2818, 2020.

[21] M. Qian, X. Liao, J. Xu et al., Key Strata Theory in Ground Control, China University of Mining and Technology Press, Beijing, China, 2000.

[22] F. He, J. Zhao, and Z. Yao, Control Theory of Stope Rock Strata, Metallurgical Industry Press, Beijing, China, 2009.

[23] Z. Xu, Elasticity, Higher Education Press, Beijing, China, 2006.

[24] S. Xie, D. Chen, Y. Sun et al., "Analysis on thin plate model of basic roof at elastic foundation boundary (I): first breaking," Journal of China Coal Society, vol. 41, no. 6, pp. 1360-1368, 2016.

[25] D. Chen, X. Wu, S. Xie et al., "Study on the thin plate model with elastic foundation boundary of overlying strata for backfill mining," Mathematical Problems in Engineering, vol. 202015 pages, 2020.

[26] F. He, D. Chen, and S. Xie, "The KDL effect on the first fracture of main roof with elastic foundation boundary," Chinese Journal of Rock Mechanics and Engineering, vol. 36, no. 6, pp. 1384-1399, 2017.

[27] X. Zhang, Efficient Solution of Differential Equations in MATLAB: Principle and Realization of Spectrum Method, China Machine Press, Beijing, China, 2016.

[28] H. Yu, Y. Zan, and S. Xu, Rock Strength Theory and its Application, China Science Press, Beijing, China, 2017.

[29] F. He, X. Li, W. He, Y. Zhao, Z. Xu, and Q. Li, "The key stratum structure morphology of longwall mechanized top coal caving mining in extra-thick coal seams: a typical case study," Advances in Civil Engineering, vol. 202013 pages, 2020.

[30] L. M. Zhang, "Numerical simulation of pressure relief for extremely thin coal seam as protection seam based on UDEC," Applied Mechanics and Materials, vol. 295-298, pp. 28792883, 2013. 